\title{
A CASE OF ACUTE DIARRHEA DUE TO THE EMERGING PATHOGEN CAMPYLOBACTER JEJUNI SUBSP. DOYLEI IN SOUTHERN CHILE
}

\author{
Heriberto Fernández ${ }^{1 *}$; Roxana Rodríguez ${ }^{1}$; Carmen Barudi²; Marta Lobos ${ }^{3}$ \\ ${ }^{1}$ Institute of Clinical Microbiology; ${ }^{2}$ Institute of Public Health; ${ }^{3}$ Institute of Nursing, Universidad Austral de Chile, Valdivia, Chile
}

Submitted: July 18, 2002; Approved: January 13, 2003

\section{SHORT COMMUNICATION}

\begin{abstract}
The first documented case of acute diarrhea due to C. jejuni subsp. doylei in Chile is reported. The clinical findings, the absence of other enteropathogens, virus or parasites and the fact that $C$. jejuni subsp. doylei was the only bacteria isolated support the assumption that it was the etiological agent of this diarrheal case.
\end{abstract}

Key words: Campylobacter jejuni subsp. doylei, enteritis, emerging pathogen

Campylobacter enteritis is the most frequent form of acute bacterial diarrhea in developed countries (1) but, in developing countries it is considered as the second or third cause of infantile diarrhea (2,3). C. jejuni subsp. jejuni and C. coli are recognized as the most common agents of campylobacteriosis. In the last years, other Campylobacter species have emerged as enteropathogenic agents in humans (1). One of them is $C$. jejuni subsp. doylei, a Gram negative s-shaped rod, isolated for the first time in Australia from children with diarrhea (4). Although their characteristics are known since 1988 (5), little information is available with regard to ecological and geographical distributions, as well as prevalence in human diarrhea.

In order to provide additional information about the occurrence of C. jejuni subsp. doylei in different parts of the world, as well as about some of the clinical and bacteriological features, we report here the first case of acute diarrhea associated to this microorganism in Southern Chile.

A 1.5 year old child was admitted at the Pediatric Emergency Clinic of the Valdivia County Hospital (Valdivia City - Chile, $73^{\circ}$ $11^{\prime}$ 'Western, $39^{\circ} 46^{\prime}$ 'Southern latitude), with a two days history of watery diarrhea associated with vomiting. The onset started with liquid mucous stools, with no blood or pus, with a purging rate of 10 to 15 times daily. On physical examination, the child presented signs of moderated dehydration and fever $\left(38.2^{\circ} \mathrm{C}\right)$. The abdomen was normal but with hyperactive bowel sounds. The patient weighed $12.8 \mathrm{Kg}$ and the height was $88.5 \mathrm{~cm}$.

Three stool samples obtained every other day, were examined for ova and parasites. Other two stool samples were obtained, one tested for rotavirus and the other cultured for enteropathogenic Enterobacteriaceae and Vibrio but not for Campylobacter spp. The screening tests for enteric parasites, rotavirus and the standard cultures for conventional bacterial enteropathogens were negative. Urine analysis, uroculture, hemograme, fecal $\mathrm{pH}$ and Benedict test results were negative or within normal parameters.

Parenteral fluid therapy and dietetic antidiarrheic regimen and no antimicrobial therapy were prescribed. The patient's conditions improved considerably being discharged home at the fourth day of hospitalization on the parent's demand.

Two days later, the patient relapsed with watery diarrhea. The stool samples were examined again for parasites, enteropathogenic Enterobacteriaceae and Vibrio as well as for Campylobacter spp. Stool culture for the classical thermophilic enteropathogenic Campylobacter species was done by direct inoculation onto a modified Skirrow medium plate (3). For the emerging Campylobacter species the membrane filter method (6) was used.

\footnotetext{
* Corresponding author. Mailing address: Institute of Clinical Microbiology, Universidad Austral de Chile, PO Box 567, Valdívia, Chile, Fax: (+5663)
} 293300. E-mail: hfernand@uach.cl 
In brief, a $47 \mathrm{~mm} 0.45 \mu \mathrm{m}$ membrane filter (Millipore) was placed on a sheep blood agar plate and various drops (10-12) of 1/10 fecal suspension in phisiological saline solution were placed onto the membrane filter. The membrane was removed after $30 \mathrm{~min}$, by which time the fluid and Campylobacter cells will have passed through. The modified Skirrow medium plate was incubated at $42^{\circ} \mathrm{C}$ for $48 \mathrm{~h}$ and the sheep blood agar plate at $37^{\circ} \mathrm{C}$ for up to five days, under microaerophilic atmosphere. A direct Gram smear was also performed, revealing thin, Gram negative curved and sshaped bacteria, resembling Campylobacter morphology. No leukocytes were observed. No parasites, rotavirus nor classical enteropathogenic bacteria were found. No growth were found on modified Skirrow medium but, after three days of incubation, pinpoint, convexe non hemolytic colonies were isolated on blood agar. Subcultures incubated at 26 and $42^{\circ} \mathrm{C}$ or aerobically failed to grow. Gram stain showed curved, s-shaped Gram negative rods. Oxidase and catalase tests gave positive reactions. Their growth and morphological characteristics as well as their biochemical properties allowed their identification as C. jejuni subsp. doylei.

After result of direct Gram stain was reported, erythromycin $(50 \mathrm{mg} / \mathrm{kg} /$ day divided in four doses for 10 days) and dietetic regimen were prescribed. This was rapidly followed by a favorable outcome without further diarrhea relapses.

In the last years it has been reported that some Campylobacter species other than $C$. jejuni subsp. jejuni and $C$. coli can produce gastroenteritis in humans (1). One of them is C. jejuni subsp. doylei that has been isolated from patients with diarrhea in Australia (4,5), South Africa (6), Malasya (7), Spain (8), Sweden (9) and Brazil (10). This species grows slowly at $37^{\circ} \mathrm{C}$ and does not grow at $26^{\circ} \mathrm{C}$ nor at $42^{\circ} \mathrm{C}$. It is hyppurate hydrolisis positive, nitrate to nitrite reduction and gamma glutamyl transferase negative and it is more susceptible than C. jejuni subsp. jejuni to cephalotin and polymyxin $(5,8)$. The strain described here was isolated at $37^{\circ} \mathrm{C}$ only in blood agar plate after a filtration procedure. It failed to grow at $26^{\circ} \mathrm{C}$ and $42^{\circ} \mathrm{C}$ and in media containing cephalotin and polymyxin and their biochemical behavior was compatible with that described for $C$. jejuni subsp. doylei.

According to the available data, C. jejuni subsp. doylei seems to produce diarrhea most likely in children under five years old (5). In this paper we report a 1.5 year old child with watery non mucous diarrhea and moderate dehydration, the latter due to vomiting and the high number of bowel movements per day. Initially, the illness presented a natural resolution but, two days after discharge, the patient relapsed with watery diarrhea, being C. jejuni subsp. doylei isolated from their stools, having a favorable outcome after erythromycin treatment.

The clinical features and the presence of liquid stools without blood and leucocytes suggest a secretory diarrhea. However, the virulence factors of $C$. jejuni subsp. doylei as well as reservoirs, ecological distribution and role in causing human illness are not yet defined. Further studies are needed to demonstrate virulence factors and to identify the reservoirs and ecological distribution. Recently, we isolated C. jejuni subsp. doylei from stools of undernourished children without diarrhea (1.9\%) and from stray dogs (6.7\%) [unpublished data]. On the other hand, it is necessary that laboratories use suitable isolation methods, such as the filtration technique, that permit the isolation of this and other emerging Campylobacter species that could be misdiagnosed when solely the traditional selective media for Campylobacter are used.

The clinical findings of this case, the absence of other common enteropathogens, virus or parasites in stools and the fact that $C$. jejuni subsp. doyle $i$ was the only bacteria isolated, support the assumption that it was the etiological agent of this diarrheal case.

This is, to our knowledge, the first reported case of acute infantile diarrhea due to C. jejuni subsp. doylei in Chile and probably the second in South America.

\section{ACKOWLEDGEMENTS}

This work received financial support from Grants FONDEDCYT 1980920 and DID-UACH 2001-S-33.

\section{RESUMO}

Um caso de diarréia aguda devido ao patógeno emergente Campylobacter jejuni subsp. doylei no sul do Chile

O primeiro caso documentado de diarréia aguda por C. jejuni subsp. doylei no sul do Chile é apresentado. As características clínicas, a ausência de outros enteropatógenos, vírus ou parasitas, e o fato de $C$. jejuni subsp. doylei ter sido a única bactéria isolada, permitem assumir que este microrganismo é o agente etiológico neste caso de diarréia.

Palavras-chave: Campylobacter jejuni subsp. doylei, enteritis, patógeno emergente.

\section{REFERENCES}

1. Allos, B.M.; Blaser, M.J. Campylobacter jejuni and the expanding spectrum of related infections. J. Clin. Infect. Dis., 20: 1092-1101, 1995

2. Fernández, H. Thermotolerant Campylobacter species associated with human diarrhea in Latin America. J. Braz. Ass. Adv. Sci. (Ciência e Cultura), 44: 39-43, 1992.

3. Fernández, H.; Kahler, K.; Salazar, R.; Ríoz, M. Prevalence of thermotolerant species of Campylobacter and their biotypes in children and domestic birds and dogs in Southern Chile. Rev. Inst. Med. Trop., 36: 433-436, 1994.

4. Steele, T.W.; Sangster, N.; Lanser, J.A. DENA relatedness and biochemical features of Campylobacter spp. isolated in Central and South Australia. J. Clin. Microbiol., 22: 71-74, 1986. 
5. Steele, T.W.; Owen, R.J. Campylobacter jejuni subsp. doylei subsp. nov., a subspecies of nitrate-negative campylobacters isolated from human clinical samples. Int. J. Syst. Bacteriol., 38: 316318,1988 .

6. Lastovica, A.J. In: Newell, D.G.; Ketley, G.M.; Feldman, R.A. (eds). Campylobacters, Helicobacters and related organisms. Plenum Press, London, 1996, p. 475-479.

7. Tay, S.T.; Puthucheary, S.D.; Devi, S.; Kautner, Y. Characterization of Campylobacters from Malasya. Singapore Med. J., 36: 282-284; 1991.
8. Jiménez, A.; Velázquez, J.B.; Rodríguez, J.; Chomón, B.; Villa, T.G. Biotyping of Campylobacter jejuni and Campylobacter coli in Spain. J. Infect., 29: 305-310, 1994.

9. Lindblom, G.B.; Sjörgen, E.; Hansson-Westerberg, J.; Kaijser, B. Campylobacter upsaliensis, Campylobacter sputorum and Campylobacter concisus as common causes of diarrhea in Sweden childrern. Scand. J. Infect. Dis., 27: 187-188, 1995.

10. Fernández, H.; Fagundes Neto, U.; Ogata, S. Acute diarrhea associated with Campylobacter jejuni subsp. doylei in São Paulo, Brazil. Ped. Infect. Dis. J., 16: 1098-1099, 1997. 